\title{
Limitación del reclutamiento de plantas
}

Javier Ruiz

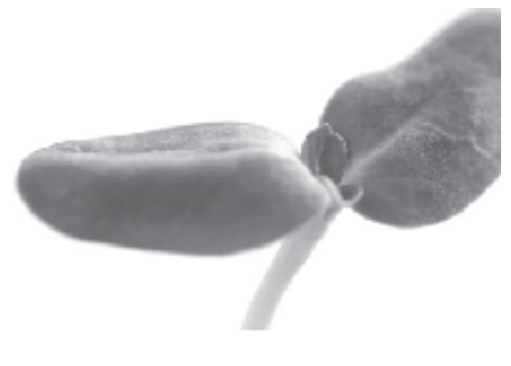

Javier Ruiz

\section{6}

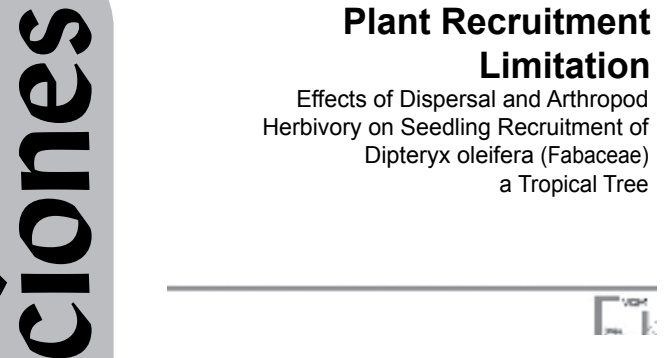

Proyecto Biodiversidad. Coordinador científico de Programa Científico Complementario. Villa Venezuela Grupo I-4661. Managua, Nicaragua. Correo electrónico: javierruizphd@gmail.com; $\quad$ www.javierruizperez. blogspot.com

Tengo mucho agrado en presentar a la comunidad científica nacional mi más reciente libro titulado: Plant Recruitment Limitation, traducido al español como: Limitación del Reclutamiento de Plantas.

El libro está estructurado en ocho capítulos. En el capítulo 1 presento el marco de trabajo general empleado, así como las preguntas de investigación: ¿Cuáles son los mecanismos biológicos responsables del mantenimiento de la alta diversidad de los bosques húmedos tropicales? Luego, en el capítulo 2 , revisé el tipo de evidencia requerida para abordar esta pregunta. Se demostró que la distribución de la sobrevivencia de las plantas es agrupada y depende directamente de la distancia al árbol adulto más cercano en un bosque en regeneración en el este de Nicaragua (capítulo 3).

Debido a que la dispersión de semillas es fundamentalmente necesaria para la distribución observada de semillas y plántulas, ésta se encuentra en los tópicos tratados en los capítulos iniciales, y luego se enfatiza en los mecanismos de dispersión y sus consecuencias para la dinámica de reclutamiento de plantas. Primero examiné una pregunta de investigación: ¿Cuál es la importancia relativa de la dispersión de semilla primaria y secundaria? (capítulo 4). Los resultados muestran que la dispersión secundaria de semillas reduce la mortalidad de semillas y se correlaciona positivamente con la sobrevivencia de semillas lejos del árbol congénere más cercano. Este tipo de dispersión, la dispersión secundaria de semillas, liberó a las semillas de los efectos negativos de la densidad asociados con los montículos de semillas congregados por los murciélagos bajo palmas utilizadas como comederos (capítulo 5).

Se examina el impacto de la presencia de arañas en la distribución y demografía de plantas. Se encontró que la presencia de arañas se correlaciona positivamente con la sobreviviencia de plántulas. Se presume que los insectos son los responsables de la 
herbivoría, de esta forma la depredación de insectos por las arañas da como resultado un efecto positivo indirecto en la sobrevivencia de plántulas (capítulo 6). Para sintetizar la serie de estudios, se comparan los resultados en el capítulo 7 . En el capítulo 8 se presentan las conclusiones y se plantea la agenda de investigación para el futuro.

Publicado por Verlag Dr. Müller Publishing House de Alemania, el libro está escrito en inglés con resúmenes en español y en inglés. Consta de 182 páginas acompañado de ilustraciones, tablas y fotografías. Los detalles del libro pueden ser consultados en Internet utilizando las palabras clave: Javier Ruiz, Plant Recruitment Limitation en el sitio: www.amazon.com 